\title{
Effects of gestational age at birth on health outcomes at 3 and 5 years of age: population based cohort study
}

\author{
(c) $(1)(9)$ OPEN ACCESS
}

\author{
Elaine M Boyle senior lecturer in neonatal medicine ${ }^{1}$, Gry Poulsen researcher in statistics and \\ epidemiology ${ }^{2}$, David J Field professor of neonatal medicine ${ }^{1}$, Jennifer J Kurinczuk director ${ }^{2}$, Dieter \\ Wolke professor of developmental psychology and individual differences ${ }^{3}$, Zarko Alfirevic head of \\ women's and children's health ${ }^{4}$, Maria A Quigley reader in statistical epidemiology ${ }^{2}$
}

${ }^{1}$ Department of Health Sciences, University of Leicester, Leicester LE1 6TP, UK; ${ }^{2}$ National Perinatal Epidemiology Unit, University of Oxford, Oxford OX3 7LF, UK; ${ }^{3}$ University of Warwick, Department of Psychology and Division of Mental Health and Wellbeing, Warwick Medical School, Coventry CV4 7AL, UK; ' University of Liverpool, Department of Women's and Children's Health, Institute of Translational Medicine, Liverpool Women's Hospital, Liverpool L8 7SS, UK

\begin{abstract}
Objective To investigate the burden of later disease associated with moderate/late preterm (32-36 weeks) and early term (37-38 weeks) birth.

Design Secondary analysis of data from the Millennium Cohort Study (MCS).
\end{abstract}

Setting Longitudinal study of infants born in the United Kingdom between 2000 and 2002.

Participants 18818 infants participated in the MCS. Effects of gestational age at birth on health outcomes at $3(n=14273)$ and 5 years $(n=14056)$ of age were analysed.

Main outcome measures Growth, hospital admissions, longstanding illness/disability, wheezing/asthma, use of prescribed drugs, and parental rating of their children's health.

Results Measures of general health, hospital admissions, and longstanding illness showed a gradient of increasing risk of poorer outcome with decreasing gestation, suggesting a "dose-response" effect of prematurity. The greatest contribution to disease burden at 3 and 5 years was in children born late/moderate preterm or early term. Population attributable fractions for having at least three hospital admissions between 9 months and 5 years were $5.7 \%$ (95\% confidence interval $2.0 \%$ to $10.0 \%)$ for birth at $32-36$ weeks and $7.2 \%(1.4 \%$ to $13.6 \%$ ) for birth at $37-38$ weeks, compared with $3.8 \%$ (1.3\% to $6.5 \%)$ for children born very preterm (<32 weeks). Similarly, $2.7 \%(1.1 \%$ to $4.3 \%), 5.4 \%$ (2.4\% to $8.6 \%$ ), and $5.4 \%$ ( $0.7 \%$ to $10.5 \%$ ) of limiting longstanding illness at 5 years were attributed to very preterm birth, moderate/late preterm birth, and early term birth.

Conclusions These results suggest that health outcomes of moderate/late preterm and early term babies are worse than those of full term babies. Additional research should quantify how much of the effect is due to maternal/fetal complications rather than prematurity itself.
Irrespective of the reason for preterm birth, large numbers of these babies present a greater burden on public health services than very preterm babies.

\section{Introduction}

Very preterm infants, born before 32 weeks of gestation, have high rates of neonatal morbidity and mortality and have therefore been the centre of most research into outcomes following preterm birth. ${ }^{1}$ In contrast, data on long term health outcomes of infants born between 32 and 36 weeks of gestation are scarce. Moderate (32-33 weeks) and late (34-36 weeks) preterm infants represent $6-7 \%$ of all births and around $75 \%$ of preterm births annually in the United Kingdom. ${ }^{2}$ Recent studies have consistently shown higher mortality, increased neonatal morbidity, and worse neurodevelopmental and educational outcomes in these infants compared with those of at least 37 weeks' gestation, ${ }^{3-12}$ although on average their problems are less severe than those of very preterm infants. ${ }^{5}$ More recently, a gradient of risk even beyond 37 weeks' gestation has been described, showing early term (37-38 weeks) infants to be at higher risk of poorer developmental and educational outcomes than full term (39-41 weeks) infants. ${ }^{13}{ }^{14}$ Health outcomes in childhood for late and moderate preterm infants have not been investigated so far. In the UK, neonatal data for babies of at least 32 weeks' gestation are not routinely collected, and these babies are not routinely followed up after discharge from neonatal hospital care. The contribution of this group to the burden of later disease associated with preterm and early term birth is therefore unclear.

We report results of a secondary analysis of publicly available data from the Millennium Cohort Study (MCS), a nationally representative prospective cohort study in the UK. This analysis 
focused on effects of gestational age on health outcomes at 3 and 5 years of age and disease burden in early childhood.

\section{Methods}

The MCS is a longitudinal study of 18818 infants born in the UK. ${ }^{15}$ It is based on a random two stage sample drawn from child benefit registers. Infants born in England and Wales between September 2000 and August 2001 and in Scotland and Northern Ireland between November 2000 and January 2002 were included if alive and living in the UK at 9 months of age. Child benefit is a financial social benefit in the UK, covering all children except those with recent or temporary immigrant status. Stratified sampling at electoral ward level with over-sampling of ethnic minority and disadvantaged areas ensured adequate representation of these populations. Trained interviewers interviewed parents and assessments were carried out in children's homes when they were 9 months, 3 years, and 5 years old.

\section{Calculation of gestational age}

Gestational age in weeks was calculated on the basis of the mother's report of her expected due date. In the MCS, this corresponded well with routine hospital records of gestational age. ${ }^{16} \mathrm{We}$ divided gestational age at birth into very preterm (23-31 weeks), moderate preterm (32-33 weeks), late preterm (34-36 weeks), early term (37-38 weeks), and full term (39-41 weeks). We excluded post-term infants (42-43 weeks) because preterm and post-term birth are known to have different causes and because comparison with hospital data showed that post-term birth was prone to misclassification in our study. ${ }^{16}$ We identified implausible combinations of birth weight and gestational age as those that were larger or smaller than the median plus or minus twice the interquartile range, using birth weight for gestational age centiles as reported by Bonellie et al. ${ }^{17}$ In cases of maternal diabetes, we considered birth weights over these limits to be plausible. These steps excluded 97 observations.

\section{Health outcomes}

Height, weight, and body mass index were assessed at 3 and 5 years. Trained interviewers measured height with a Leicester stadiometer and recorded it to the nearest completed millimetre. They measured weight without outdoor clothes or shoes by using Tanita HD 305 scales and recorded it in kilograms to one decimal place. Children were categorised as underweight, normal weight, overweight, or obese according to age and sex specific cut-offs for body mass index. ${ }^{18} 19$

Parental reports of the number of hospital admissions not related to accidents since birth or the previous interview were collected at 9 months and at 3 and 5 years. Parental reports of any longstanding illness, disability, or infirmity of more than three months' duration and diagnosed by a health professional were collected at 3 and 5 years. We defined limiting longstanding illness as illness that limited activities normal for the child's age group. Parental reports of wheezing within the previous 12 months and asthma were collected at 3 and 5 years. Parental reports of the use of prescribed drugs, coded according to the British National Formulary were collected at 5 years. Parents' ratings of children's health as excellent, very good, good, fair, or poor were collected at 5 years.

\section{Statistical methods}

We restricted analyses to births for which the natural mother was the respondent at the 9 month interview. We modelled binary outcomes by using logistic regression and continuous outcomes by using linear regression with the full term group as the reference. All analyses accounted for multiples by adjusting for multiple birth status as a linear regression term and allowing for clustering by family. We adjusted analyses for the child's sex, ethnicity (white British, Indian, Black Caribbean/Black African, Bangladeshi/Pakistani, other), and age at interview; for mother's education (academic degree, completed high school, completed basic compulsory school, overseas qualifications, no formal qualifications), marital status (married, cohabiting, single), occupation (managerial/professional, intermediate, self employed/small employer, lower supervisory/technical occupations, routine/semi-routine, long term unemployed), and age at delivery; birth order; duration of breast feeding; and maternal smoking (non-smoker, stopped smoking during pregnancy, smoked throughout pregnancy) and alcohol intake (never, moderate (not more than 3-6 units per week or 3-5 units per occasion), heavy ( $\geq 7$ units per week or $\geq 6$ units per occasion)) during pregnancy.

We estimated population attributable fractions associated with preterm and early term birth as (proportion of cases exposed $) \times(\mathrm{OR}-1) / \mathrm{OR}$, where $\mathrm{OR}$ is the adjusted odds ratio from the logistic model. We calculated approximate $95 \%$ confidence intervals for population attributable fractions by using the Bonferroni inequality method. ${ }^{20}$ All analyses allowed for the clustered, stratified sample design by using the "survey commands" in Stata version 11. All reported percentages and means are weighted according to sampling design and non-response. ${ }^{21} 22$

\section{Study dropout}

The response rate was $85 \%$ for the first interview. ${ }^{15}$ At 3 and 5 years, $78 \%$ and $79 \%$ of families eligible for follow-up were interviewed. ${ }^{23}$ We used non-response weights to adjust our results for differential participation and dropout associated with socioeconomic indicators and family mobility. ${ }^{22}{ }^{23}$ The percentage of preterm infants in the sample at the 9 months interview was $8.4 \%$ compared with $7.3 \%$ in national data on gestational age, calculated for survivors one year after birth. ${ }^{2}$ We found no associations between risk of dropout and birth weight, length of infants' neonatal hospital stay, or having special neonatal care. However, admission to hospital three or more times during the first nine months was associated with increased dropout, and we found some evidence of increased dropout in children born before 32 weeks of gestation. In summary, families with preterm and term infants were equally likely to participate in the MCS, but the small number of very preterm infants who were very ill during their early life may be under-represented.

\section{Results}

The first interview included parents of 18818 children; we excluded 1099 because of missing or implausible gestational age, gestation at birth of greater than 41 weeks, or the natural mother not being the respondent, leaving 17719 . Of this initial sample, parents of $14273(81 \%)$ children were interviewed at 3 years and $14056(79 \%)$ at 5 years (fig $1 \Downarrow$ ).

Table $1 \Downarrow$ shows the maternal characteristics at 9 months, and table $2 \Downarrow$ shows characteristics of the children. A greater proportion of babies born before 32 weeks were from ethnic groups other than white British compared with the remaining 
gestation cohorts. Proportions of multiple births and firstborn infants were higher in the preterm groups compared with term groups. Mothers of infants born before 37 weeks of gestation were slightly more likely to be single and less likely to have educational qualifications or work in a managerial position than those of mature babies. Mothers of very preterm infants were more likely to smoke and less likely to breast feed for four or more months than were those who delivered at 37 weeks or later.

\section{Growth and weight gain}

Height and weight decreased across gestational age groups with increasing prematurity, and this effect was present at both 3 and 5 year assessments (table $3 \Downarrow$ ). We also found several differences between specific gestational age groups. Figure $2 \Downarrow$ shows the classification of body mass index by gestational age. At 3 and 5 years, the highest proportion of children classified as obese was in the late preterm group. Children born very preterm were most likely to be classified as underweight at both 3 and 5 years.

\section{General health status}

Measures of general health, hospital admissions, and longstanding illness showed similar patterns. A gradient of increasing risk of poorer outcomes with increasing prematurity extended across the range of gestational age groups (tables $4 \Downarrow$ and $5 \Downarrow$ ). With respect to the first nine months of life, the most common primary reasons for admission to hospital were respiratory disorders, including chest infection and wheezing or asthma; gastrointestinal disorders, including gastroenteritis and gastro-oesophageal reflux; and viral illness or fever. The proportion of infants admitted to hospital for chest infections increased with increasing prematurity (data not shown). For all general health measures, the odds ratios associated with moderate and late preterm and early term birth were smaller than those associated with very preterm birth, but the number of children with health problems was much larger for children born at moderate and late preterm or early term. The population attributable fractions associated with moderate/late preterm and early term birth were larger than those for very preterm birth: $5.7 \%$ and $7.2 \%$ compared with $3.8 \%$ for having at least three hospital admissions between 9 months and 5 years, $7.7 \%$ and $0.2 \%$ compared with $3.2 \%$ for limiting longstanding illness at 3 years, and $5.4 \%$ and $5.4 \%$ compared with $2.7 \%$ for limiting longstanding illness at 5 years.

Parents' subjective rating of their children's health at 5 years of age also broadly reflected a similar pattern. Children's health was more likely to be perceived as poor with increasing degrees of prematurity (table $6 \Downarrow$ ).

\section{Asthma and wheeze}

Asthma and wheezing also showed a gradient of effect with increasing prematurity, but with particularly high odds in children born very preterm (tables $7 \Downarrow$ and $8 \Downarrow$ ). At 5 years, treatments for asthma were the most commonly prescribed drugs; the odds ratios for needing asthma treatment increased with increasing prematurity. We found no difference in use of prescribed drugs according to gestation at birth after exclusion of drugs for asthma (data not shown).

\section{Discussion}

This is the first large population based study in the UK to explore the relation between gestational age at birth and later health outcomes. Our results consistently showed a gradient of worsening health outcomes with decreasing gestation at birth. This gradient extended across the whole range of gestational age groups, from very preterm to full term, suggesting a "dose-response" effect of prematurity. However, although the risks of health problems were highest in the very preterm group, the greater number of late preterm and early term births resulted in larger attributable fractions at these stages of pregnancy. Our results challenge widely held views that long term health outcomes for moderate and late preterm babies are similar to those for babies born at full term. The results also challenge perceptions about outcomes for babies born during part of the period of gestation that has traditionally been regarded as "term" (37-38 weeks).

Health measures that indicated increasing adverse effects with decreasing gestation included growth, weight gain, longstanding illness, and asthma or wheeze. Furthermore, the proportion of babies needing three or more hospital admissions during the first nine months increased with decreasing gestation; respiratory or gastrointestinal disorders were the most common reasons for admission. Parents' assessments of their children's health were in keeping with these findings and showed that they were more likely to rate their child's health as poor or fair in the preterm groups.

\section{Strengths and limitations of study}

This study represents the first data for health outcomes across the full range of gestational age groups for babies born this century. A major strength of the study is that the data are representative of the UK population. Data collection included multiple health measures providing a broad range of information on children through infancy and childhood and allowing adjustment for potential confounding factors known to affect children's health and development. The study also benefited from oversampling of socially disadvantaged areas and non-response weighting to allow for differential participation and dropout.

A limitation of the study is that gestation was estimated according to maternal report. Agreement between maternal report and hospital records was $94 \%$ for gestation plus or minus one week. ${ }^{16}$ This method may result in some misclassification, however, although this is less problematic when data are used in groups. A further limitation is the study's reliance on parental report of children's health status, without verification of data by use of medical records. With the exception of anthropometric data, parents provided information on all outcomes. This method is prone to potential recall bias, which may lead to under-reporting or over-reporting of outcomes. However, studies have shown that parental report of episodes of acute illness and healthcare correlates well with medical records. ${ }^{24}{ }^{25}$ Bias and overestimation of effects may potentially have been introduced if worried parents of sick children tended to respond more frequently than those whose children remained well; lack of detailed information about severity of illness is a further weakness. Conversely, children admitted to hospital more than three times during the first nine months had disproportionately high dropout at 3 and 5 years, which may lead to underestimation of adverse outcomes at later follow-up.

\section{Comparison with other studies}

Interest in outcomes for more mature preterm babies has increased recently, following publication of work showing a higher risk of mortality and morbidity in babies of 32-36 weeks' gestation compared with those born at 37 weeks or later. ${ }^{46}$ In terms of readmission to hospital, previous research has focused 
mainly on the first year of life and has found that late preterm babies required readmission during the first months of life more often than did those born at 37 weeks or later. ${ }^{26-28}$ Similarly, Bird et al showed increased healthcare use and costs in the first year associated with late preterm birth compared with babies of at least 37 weeks' gestation. ${ }^{29}$ Our data enabled us to examine admissions up to 5 years of age and also in less mature babies, and we showed a similar gradient of risk. When interpreting such findings, it is important to remember that the initial neonatal stay, particularly in very preterm babies, may be prolonged, thereby reducing the opportunity for readmission during the first months of life. However, we saw a similar pattern across gestational age groups for admissions to hospital between 9 months and 5 years. When considering types of morbidity, McLaurin et al found that, in infants born at 33-36 weeks of gestation, respiratory and gastrointestinal disorders accounted for half of the admissions. ${ }^{27}$ Our results were consistent with this and also showed an increased risk of asthma and wheeze in these infants compared with infants born at term. In contrast, Abe et al were unable to show a significant association between late preterm birth and risk of developing asthma. ${ }^{30}$

\section{Implications for policy and service provision}

In the absence of data from prospective studies specifically focusing on moderate preterm, late preterm, and early term birth, this study provides information on the effect of gestation at birth on use of healthcare services to inform planning and provision of future healthcare for infants and children. The findings also, of course, have implications for obstetricians managing high risk pregnancies.

Research and resources have, in recent years, been directed towards very preterm babies who are at the highest risk of neonatal morbidity and poor outcomes. However, this small group of babies (approximately 8000 births annually in England) is far outnumbered by more mature preterm babies, born at 32-36 weeks. ${ }^{2}$ This group has been understudied until recently, and babies of this gestation, although immature, have been considered to be at minimally greater risk of adverse outcomes than babies born at 37 weeks or later. Even less well understood are the risks associated with birth at 37-38 weeks (125 000 births annually ${ }^{2}$ ), as this has been thought to represent term gestation. Our study casts doubt on these perceptions and highlights differences between these babies, now more appropriately classed as early term, and those born just one or two weeks later. In interpreting our results, we acknowledge that the groups may differ for reasons other than simply gestation at birth. Significant obstetric concerns in late pregnancy commonly lead to induction or caesarean section before full term, and the early term group is thus likely to contain infants who might be predicted to have a poorer outcome by virtue of intrauterine compromise, rather than prematurity itself. In our study, data were not available on the indications for delivery. Nevertheless, irrespective of the reason for delivery, large numbers of relatively mature babies who are potentially at risk means that, although their problems are subtler than those of very preterm babies, they are more numerous and therefore likely to present a greater burden for health and education services.

Advances in neonatal and obstetric care have led to increasing survival and improved short term outcomes at all preterm gestations. This, in turn, has led to increased confidence both in prolongation of complicated pregnancies at very preterm gestations and in early intervention with delivery for problems at later stages in pregnancy but before full term has been reached. This, together with the influence of greater maternal choice regarding timing of delivery, has led to increasing numbers of babies born at 32-38 weeks of gestation. The findings of our study and others should prompt exploration of obstetric decision making processes at moderate preterm, late preterm, and early term gestations.

\section{Conclusions}

Continuing to view health outcomes of babies as dichotomous preterm/term outcomes is inappropriate, as our study shows a continuum of increasing risk of adverse outcome with increasing prematurity, even approaching full term gestation. Further exploration of the factors that influence health outcomes for children born at early term gestations is needed. If future studies confirm our findings, the implications are substantial both for provision of obstetric services and for planning and delivery of healthcare services for children during the early years of life.

Contributors: All authors contributed to the design of the study. GP and $M A Q$ did the data analysis. All authors interpreted the results. EMB,

DJF, and GP drafted the paper. JJK, DW, ZA, and MAQ reviewed and edited the paper. MAQ is the guarantor.

Funding: The BUPA Foundation funded the study but had no role in the study design, data analysis and interpretation, or writing of the report.

Competing interests: All authors have completed the Unified Competing Interest form at www.icmje.org/coi_disclosure.pdf (available on request from the corresponding author) and declare: no support from any organisation for the submitted work; no financial relationships with any organisations that might have an interest in the submitted work in the previous three years; no other relationships or activities that could appear to have influenced the submitted work.

Ethical approval: This research involved secondary analysis of the Millennium Cohort Study and therefore did not require ethical approval. The multi-centre research ethics committee granted ethical approval for the MCS.

Data sharing: The datasets are available on the UK Data Archive. Further information about the study and data can be found at www.cls.ioe.ac. uk/.

1 Wood NS, Marlow N, Costeloe K, Gibson AT, Wilkinson AR. Neurologic and developmental disability after extremely preterm birth. N Engl J Med 2000;343:378-84.

2 Moser K, Macfarlane A, Chow YH, Hilder L, Dattani N. Introducing new data on gestation-specific infant mortality among babies born in 2005 in England and Wales. Health Stat Q 2007;13:27.

3 Kramer MS, Demissie K, Yang H, Platt RW, Sauve R, Liston R. The contribution of mild and moderate preterm birth to infant mortality. JAMA 2000;284:843-9.

4 Tomashek KM, Shapiro-Mendoza CK, Davidoff MJ, Petrini JR. Differences in mortality between late-preterm and term singleton infants in the United States, 1995-2002. J Pediatr 2007; 151:450-6,456.e1.

5 Escobar GJ, Clark RH, Greene JD. Short-term outcomes of infants born at 35 and 36 weeks' gestation: we need to ask more questions. Semin Perinatol 2006;30:28-33.

6 McIntire DD, Leveno KJ. Neonatal mortality and morbidity rates in late preterm births compared with births at term. Obstet Gynecol 2008;111:35-41.

7 Wang ML, Dorer DJ, Fleming MP, Catlin EA. Clinical outcomes of near-term infants. Pediatrics 2004;114:372-6.

8 Baron IS, Erickson K, Ahronovich MD, Baker R, Litman FR. Cognitive deficit in preschoolers born late-preterm. Early Hum Dev 2011;87:115-9.

9 Petrini JR, Dias T, McCormick MC, Massolo ML, Green NS, Escobar GJ. Increased risk of adverse neurological development for late preterm infants. J Pediatr 2009;154:169-76.

10 Talge NM, Holzman C, Wang J, Lucia V, Gardiner J, Breslau N. Late-preterm birth and its association with cognitive and socioemotional outcomes at 6 years of age. Pediatrics 2010;126:1124-31.

11 Chyi LJ, Lee HC, Hintz SR, Gould JB, Sutcliffe TL. School outcomes of late preterm infants: special needs and challenges for infants born at 32 to 36 weeks' gestation. $J$ Pediatr 2008;153:25-31.

12 Van Baar AL, Vermaas J, Knots E, de Kleine MJ, Soons P. Functioning at school age of moderately preterm children born at 32 to 36 weeks' gestational age. Pediatrics 2009;124:251-7.

13 Lindstrom K, Lindblad F, Hjern A. Psychiatric morbidity in adolescents and young adults born preterm: a Swedish national cohort study. Pediatrics 2009;123:e47-53.

14 MacKay DF, Smith GC, Dobbie R, Pell JP. Gestational age at delivery and special educational need: retrospective cohort study of 407,503 schoolchildren. PLOS Med 2010;7:e1000289.

15 Centre of Longitudinal Studies. Millennium Cohort Study first, second, third and fourth surveys-a guide to the datasets. Centre of Longitudinal Studies, Institute of Education, 2010. 


\section{What is already known on this topic}

Moderate/late preterm infants (32-36 weeks' gestation) have increased neonatal morbidity and mortality compared with those born at 37 weeks or later

Research into long term health outcomes of infants born moderate/late preterm and early term (37-38 weeks) compared with those of full term (39-41 weeks) infants is sparse

\section{What this study adds}

A gradient of increasing risk of poorer health outcomes with decreasing gestation at birth exists, extending from full term to very preterm gestations

The greatest contribution to overall disease burden at age 3 and 5 years is in children born late/moderate preterm or early term (37-38 weeks)

These findings have implications for the provision of obstetric and neonatal services and for planning and delivery of later healthcare services for children

16 Poulsen G, Kurinczuk JJ, Wolke D, Boyle EM, Field D, Alfirevic Z, et al. Accurate reporting of expected delivery date by mothers 9 months after birth. J Clin Epidemio 2011;64:1444-50.

17 Bonellie S, Chalmers J, Gray R, Greer I, Jarvis S, Williams C. Centile charts for birthweigh for gestational age for Scottish singleton births. BMC Pregnancy Childbirth 2008:8:5.

18 Cole TJ, Bellizzi MC, Flegal KM, Dietz WH. Establishing a standard definition for child overweight and obesity worldwide: international survey. BMJ 2000;320:1240-3.

19 Cole TJ, Flegal KM, Nicholls D, Jackson AA. Body mass index cut offs to define thinness in children and adolescents: international survey. BMJ 2007;335:194

20 Natarajan S, Lipsitz SR, Rimm E. A simple method of determining confidence intervals for population attributable risk from complex surveys. Stat Med 2007;26:3229-39.

21 Plewis I. Millennium Cohort Study first survey: technical report on sampling. 4th ed. Centre for Longitudinal Studies, Institute of Education, 2007.

22 Plewis I. Non-response in a birth cohort study: the case of the Millennium Cohort Study. Int J Soc Res Methodol 2007;10:325-34.

23 Ketende SC. Millennium Cohort Study: technical report on response. 2nd ed. Centre for Longitudinal Studies, Institute of Education, 2008.

24 Vernacchio L, Vezina RM, Ozonoff A, Mitchell AA. Validity of parental reporting of recent episodes of acute otitis media: a Slone Center Office-Based Research (SCOR) Network study. J Am Board Fam Med 2007;20:160-3.

25 D'Souza-Vazirani D, Minkovitz CS, Strobino DM. Validity of maternal report of acute health care use for children younger than 3 years. Arch Pediatr Adolesc Med 2005;159:167-72.
26 Escobar GJ, Greene JD, Hulac P, Kincannon E, Bischoff K, Gardner MN, et al. Rehospitalisation after birth hospitalisation: patterns among infants of all gestations. Arch Dis Child 2005;90:125-31.

27 McLaurin KK, Hall CB, Jackson EA, Owens OV, Mahadevia PJ. Persistence of morbidity and cost differences between late-preterm and term infants during the first year of life. Pediatrics 2009;123:653-9.

28 Oddie SJ, Hammal D, Richmond S, Parker L. Early discharge and readmission to hospital in the first month of life in the Northern Region of the UK during 1998: a case cohort study. Arch Dis Child 2005;90:119-24.

29 Bird TM, Bronstein JM, Hall RW, Lowery CL, Nugent R, Mays GP Late preterm infants: birth outcomes and health care utilization in the first year. Pediatrics 2010;126:e311-9.

30 Abe K, Shapiro-Mendoza CK, Hall LR, Satten GA. Late preterm birth and risk of developing asthma. J Pediatr 2010;157:74-8.

Accepted: 5 December 2011

\section{Cite this as: BMJ 2012;344:e896}

This is an open-access article distributed under the terms of the Creative Commons Attribution Non-commercial License, which permits use, distribution, and reproduction in any medium, provided the original work is properly cited, the use is non commercial and is otherwise in compliance with the license. See: http://creativecommons.org/licenses/bync/2.0/ and http://creativecommons.org/licenses/by-nc/2.0/legalcode. 


\section{Tables}

Table 1 | Characteristics of mothers of children included in analysis. Values are numbers (percentages) unless stated otherwise Gestational age of babies at birth (weeks)

\begin{tabular}{|c|c|c|c|c|c|c|}
\hline \multirow[b]{2}{*}{ Characteristic } & \multicolumn{5}{|c|}{ Gestational age of babies at birth (weeks) } & \multirow{2}{*}{$\begin{array}{l}\text { P values comparing } \\
\text { gestational age groups }\end{array}$} \\
\hline & $<32(n=225)$ & $32-33(n=192)$ & $34-36(n=1107)$ & $37-38(n=3655)$ & $39-41(n=12540)$ & \\
\hline Mean (SD) age at time of child's birth (years) & $28.5(6.2)$ & $29.9(6.0)$ & $28.9(6.2)$ & $29.2(5.9)$ & $28.7(5.8)$ & 0.006 \\
\hline Single mother & $44(17.2)$ & $25(8.8)$ & $212(16.0)$ & $617(13.9)$ & $2082(14.0)$ & 0.04 \\
\hline \multicolumn{6}{|l|}{ Socioeconomic status: } & 0.87 \\
\hline Managerial and professional & $57(26.1)$ & $43(26.6)$ & $282(29.1)$ & $943(29.6)$ & $3358(30.6)$ & \\
\hline Long term unemployed & $21(7.0)$ & $24(9.4)$ & $124(8.9)$ & $407(8.4)$ & $1420(8.1)$ & \\
\hline \multicolumn{6}{|l|}{ Education: } & 0.001 \\
\hline Degree & $61(28.8)$ & $52(31.2)$ & $310(9.7)$ & $1017(30.8)$ & $3756(33.8)$ & \\
\hline No qualifications & $52(20.9)$ & $28(11.7)$ & $189(14.5)$ & $626(13.5)$ & $1932(11.9)$ & \\
\hline Moderate/heavy alcohol use during pregnancy $\dagger$ & $14(7.3)$ & $16(8.4)$ & $71(7.8)$ & $236(6.6)$ & $880(7.3)$ & 0.03 \\
\hline Smoked during pregnancy & $63(27.7)$ & $45(19.1)$ & $307(25.4)$ & $851(22.2)$ & $2773(20.4)$ & 0.007 \\
\hline \multicolumn{6}{|l|}{ Duration of breastfeeding: } & $<0.001$ \\
\hline Never & $71(28.9)$ & $58(29.8)$ & $445(36.8)$ & $1333(33.0)$ & $4195(29.4)$ & \\
\hline$\geq 4$ months & $38(17.4)$ & $35(21.3)$ & 229 (22.9) & $944(28.4)$ & $3870(34.5)$ & \\
\hline
\end{tabular}

Means and percentages are weighted with sampling and non-response weights

${ }^{*} \chi^{2}$ tests for categorical variables and $F$ tests for continuous variables; calculated for weighted, clustered data.

$\dagger \geq 3$ units/week or $\geq 3$ units/occasion. 
Table 2| Characteristics of children from Millennium Cohort Study included in this analysis. Values are numbers (percentages) unless stated otherwise

\begin{tabular}{|c|c|c|c|c|c|c|}
\hline \multirow[b]{2}{*}{ Characteristics } & \multicolumn{5}{|c|}{ Gestational age at birth (weeks) } & \multirow{2}{*}{$\begin{array}{l}\text { P values comparing } \\
\text { gestational age groups }\end{array}$} \\
\hline & $<32(n=225)$ & $32-33(n=192)$ & $34-36(n=1107)$ & $37-38(n=3655)$ & $39-41(n=12540)$ & \\
\hline Mean (SD) birth weight (kg) & $1.3(0.4)$ & $2.0(0.4)$ & $2.6(0.5)$ & $3.2(0.5)$ & $3.5(0.5)$ & $<0.001$ \\
\hline Male sex & $123(54.9)$ & $105(59.7)$ & $587(53.5)$ & $1902(51.5)$ & $6356(50.6)$ & 0.13 \\
\hline \multicolumn{6}{|l|}{ Ethnic group: } & \multirow[t]{3}{*}{0.032} \\
\hline White British & $176(80.4)$ & $159(88.4)$ & $927(88.6)$ & $2986(85.8)$ & $10482(87.8)$ & \\
\hline Other† & $49(19.6)$ & $33(11.6)$ & $179(11.4)$ & $669(14.2)$ & $2053(12.2)$ & \\
\hline Multiple birth & $52(21.4)$ & $42(27.0)$ & $184(17.5)$ & $179(5.0)$ & $55(0.4)$ & $<0.001$ \\
\hline First born & $112(50.1)$ & $91(51)$ & $492(44.9)$ & $1356(37.3)$ & $5448(43.4)$ & $<0.001$ \\
\hline $\begin{array}{l}\text { Mean (SD) length of neonatal hospital stay } \\
\text { (weeks) }\end{array}$ & $9.2(6.7)$ & $3.2(1.7)$ & $1.4(2.1)$ & $0.5(0.7)$ & $0.4(0.8)$ & $<0.001$ \\
\hline Mean (SD) age at 3 year interview (years) & $3.1(0.2)$ & $3.1(0.2)$ & $3.1(0.2)$ & $3.1(0.2)$ & $3.1(0.2)$ & 0.91 \\
\hline Mean (SD) age at 5 year interview (years) & $5.1(0.2)$ & $5.2(0.2)$ & $5.2(0.2)$ & $5.2(0.2)$ & $5.2(0.2)$ & $<0.001$ \\
\hline
\end{tabular}

Means and percentages are weighted with sampling and non-response weights

${ }^{*} \chi^{2}$ tests for categorical variables and $F$ tests for continuous variables; calculated for weighted, clustered data.

†Mixed, Indian, black Caribbean/black African, Bangladeshi/Pakistani, other. 


\begin{tabular}{|c|c|c|c|c|c|}
\hline \multirow{2}{*}{$\begin{array}{l}\text { Table } 3 \mid \\
\text { weeks }\end{array}$} & \multicolumn{5}{|c|}{ Gestational age at birth (weeks) } \\
\hline & $<32$ & $32-33$ & $34-36$ & $37-38$ & $39-41$ \\
\hline \multicolumn{6}{|l|}{ Height in $\mathbf{c m}$} \\
\hline At 3 years: & $(n=150)$ & $(n=147)$ & $(n=797)$ & $(\mathrm{n}=2701)$ & $(n=9445)$ \\
\hline Mean $(95 \% \mathrm{Cl})$ & 93.2 (92.2 to 94.1$)$ & 95.2 (94.4 to 96.1$)$ & 95.2 (94.8 to 95.6$)$ & 95.6 (95.4 to 95.8$)$ & 96.0 (95.9 to 96.1$)$ \\
\hline $\begin{array}{l}\text { Unadjusted difference }(95 \% \\
\mathrm{Cl})\end{array}$ & $-2.8(-3.7$ to -1.8$)$ & $-0.6(-1.6$ to 0.3$)$ & $-0.7(-1.1$ to -0.3$)$ & $-0.4(-0.6$ to -0.1$)$ & 0 \\
\hline Adjusted difference $(95 \% \mathrm{Cl})^{\star}$ & $-2.9(-3.8$ to -2.1$)$ & $-0.9(-1.9$ to 0.0$)$ & $-0.8(-1.1$ to -0.4$)$ & $-0.4(-0.6$ to -0.2$)$ & 0 \\
\hline $\begin{array}{l}\text { Adjusted for corrected age } \\
(95 \% \mathrm{Cl})^{*}\end{array}$ & $-1.4(-2.3$ to -0.5$)$ & $0.1(-0.9$ to 1.0$)$ & $-0.1(-0.5$ to 0.3$)$ & $-0.1(-0.3$ to 0.1$)$ & 0 \\
\hline At 5 years: & $(n=161)$ & $(n=145)$ & $(n=844)$ & $(\mathrm{n}=2817)$ & $(n=9869)$ \\
\hline Mean $(95 \% \mathrm{Cl})$ & $107.3(106.1$ to 108.5$)$ & $109.5(108.4$ to 110.6$)$ & 109.8 (109.4 to 110.3$)$ & $110.7(110.4$ to 110.9$)$ & $\begin{array}{c}110.8(110.7 \text { to } \\
111)\end{array}$ \\
\hline $\begin{array}{l}\text { Unadjusted difference }(95 \% \\
\mathrm{Cl})\end{array}$ & $-3.4(-4.6$ to -2.3$)$ & $-1.2(-2.3$ to -0.1$)$ & $-0.9(-1.4$ to -0.4$)$ & $-0.1(-0.4$ to 0.1$)$ & 0 \\
\hline Adjusted difference $(95 \% \mathrm{Cl})^{*}$ & $-3.1(-4.1$ to -2.0$)$ & $-1.3(-2.3$ to -0.3$)$ & $-0.8(-1.3$ to -0.4$)$ & $-0.2(-0.5$ to 0$)$ & 0 \\
\hline $\begin{array}{l}\text { Adjusted for corrected age* } \\
(95 \% \mathrm{Cl})\end{array}$ & $-1.7(-2.7$ to -0.6$)$ & $-0.4(-1.4$ to 0.6$)$ & $-0.2(-0.7$ to 0.2$)$ & $0.1(-0.2$ to 0.3$)$ & 0 \\
\hline \multicolumn{6}{|l|}{ Weight in kg } \\
\hline At 3 years: & $(n=149)$ & $(n=149)$ & $(n=807)$ & $(n=2729)$ & $(n=9570)$ \\
\hline Mean $(95 \% \mathrm{Cl})$ & $13.9(13.4$ to 14.3$)$ & $14.7(14.3$ to 15.1$)$ & $15.3(15.0$ to 15.5$)$ & $15.4(15.3$ to 15.5$)$ & $15.6(15.5$ to 15.6$)$ \\
\hline $\begin{array}{l}\text { Unadjusted difference }(95 \% \\
\mathrm{Cl})\end{array}$ & $-1.5(-2.0$ to -1.1$)$ & $-0.7(-1.1$ to -0.3$)$ & $-0.2(-0.4$ to 0.0$)$ & $-0.1(-0.2$ to 0.0$)$ & 0 \\
\hline Adjusted ${ }^{*}$ difference $(95 \% \mathrm{Cl})$ & $-1.6(-2.0$ to -1.2$)$ & $-0.8(-1.2$ to -0.4$)$ & $-0.2(-0.5$ to 0.0$)$ & $-0.1(-0.2$ to 0.0$)$ & 0 \\
\hline $\begin{array}{l}\text { Adjusted for corrected age* } \\
(95 \% \mathrm{Cl})\end{array}$ & $-1.1(-1.5$ to -0.7$)$ & $-0.5(-0.9$ to -0.1$)$ & $0.0(-0.3$ to 0.2$)$ & $0.0(-0.1$ to 0.1$)$ & 0 \\
\hline At 5 years: & $(n=161)$ & $(n=145)$ & $(n=848)$ & $(\mathrm{n}=2818)$ & $(n=9864)$ \\
\hline Mean $(95 \% \mathrm{Cl})$ & $18.3(17.5$ to 19.1$)$ & $18.8(18.3$ to 19.3$)$ & 19.8 (19.4 to 20.1$)$ & 20.1 (19.9 to 20.2) & 20.2 (20.1 to 20.2$)$ \\
\hline $\begin{array}{l}\text { Unadjusted difference }(95 \% \\
\mathrm{Cl})\end{array}$ & $-1.7(-2.5$ to -0.9$)$ & $-1.1(-1.7$ to -0.6$)$ & $-0.3(-0.6$ to 0.0$)$ & $-0.1(-0.2$ to 0.1$)$ & 0 \\
\hline Adjusted* difference $(95 \% \mathrm{Cl})$ & $-1.7(-2.4$ to -0.9$)$ & $-1.2(-1.7$ to -0.7$)$ & $-0.3(-0.6$ to -0.1$)$ & $-0.1(-0.3$ to 0.0$)$ & 0 \\
\hline $\begin{array}{l}\text { Adjusted for corrected age* } \\
(95 \% \mathrm{Cl})\end{array}$ & $-1.1(-1.9$ to -0.4$)$ & $-0.9(-1.3$ to -0.4$)$ & $-0.1(-0.4$ to 0.2$)$ & $0.0(-0.2$ to 0.2$)$ & 0 \\
\hline
\end{tabular}

Means and mean differences are weighted with sampling and non-response weights.

*Adjusted for child's age at interview, sex, and ethnicity; mother's age at birth, marital status, education, and occupation; whether child was mother's firstborn; whether child was ever breast fed; and smoking and drinking during pregnancy. 


\begin{tabular}{|c|c|c|c|c|c|}
\hline \multirow[b]{2}{*}{$\geq 3$ hospital admissions } & \multicolumn{5}{|c|}{ Gestation at birth (weeks) } \\
\hline & $<32$ & $32-33$ & $34-36$ & $37-38$ & $39-41$ \\
\hline Birth to 9 months: & $(n=225)$ & $(n=192)$ & $(n=1107)$ & $(n=3655)$ & $(n=12538)$ \\
\hline No (\%) & $16(6.6)$ & $7(3.5)$ & $28(2.9)$ & $39(1.2)$ & $86(0.6)$ \\
\hline Unadjusted odds ratio $(95 \% \mathrm{Cl})$ & 14.1 (7.2 to 27.7$)$ & 7.7 (2.9 to 20.3$)$ & 5.6 (3.3 to 9.7$)$ & $2.0(1.4$ to 3.1$)$ & 1 \\
\hline Adjusted* odds ratio $(95 \% \mathrm{Cl})$ & 13.7 (6.5 to 29.2$)$ & $7.8(2.9$ to 20.7$)$ & 5.1 (3.0 to 8.8$)$ & $1.9(1.3$ to 2.9$)$ & 1 \\
\hline \multirow{2}{*}{$\begin{array}{l}\text { Adjusted }^{*} \text { population } \\
\text { attributable fraction-\% (95\% } \\
\text { Cl) }\end{array}$} & $7.2(2.3$ to 12.4$)$ & $3.4(0.1$ to 7.6$)$ & $14.3(6.3$ to 23.1$)$ & \multirow[t]{2}{*}{11.8 (3.0 to 21.7 ) } & \multirow[t]{2}{*}{-} \\
\hline & \multicolumn{3}{|c|}{17.7 (8.6 to 27.4$)$} & & \\
\hline 9 months to 5 years: & $(n=147)$ & $(n=139)$ & $(n=745)$ & $(\mathrm{n}=2563)$ & $(\mathrm{n}=8989)$ \\
\hline No (\%) & $21(13.6)$ & $11(6.9)$ & $44(4.9)$ & $123(3.9)$ & $285(2.8)$ \\
\hline Unadjusted odds ratio $(95 \% \mathrm{Cl})$ & 6.2 (3.4 to 11.4$)$ & 3.0 (1.4 to 6.3$)$ & 2.0 (1.4 to 2.8$)$ & 1.5 (1.1 to 1.9$)$ & 1 \\
\hline Adjusted odds ratio $(95 \% \mathrm{Cl})$ & $6.0(3.2$ to 11.4$)$ & 3.0 (1.4 to 6.2$)$ & 1.91 .3 to 2.7$)$ & $1.4(1.1$ to 1.8$)$ & 1 \\
\hline \multirow{2}{*}{$\begin{array}{l}\text { Adjusted }{ }^{*} \text { population } \\
\text { attributable fraction—\% (95\% } \\
\text { Cl) }\end{array}$} & \multirow[t]{2}{*}{$3.8(1.3$ to 6.5$)$} & $1.6(0.1$ to 3.7$)$ & $4.1(1.0$ to 7.7$)$ & \multirow[t]{2}{*}{$7.2(1.4$ to 13.6$)$} & \multirow[t]{2}{*}{-} \\
\hline & & \multicolumn{2}{|c|}{$5.7(2.0$ to 10.0$)$} & & \\
\hline
\end{tabular}

All percentages and odds ratios are weighted with sampling and non-response weights.

*Adjusted for child's age at interview, sex, and ethnicity; maternal age at birth, marital status, education, and occupation; whether child was mother's firstborn; duration of breast feeding; and maternal smoking and alcohol intake during pregnancy. 


\begin{tabular}{|c|c|c|c|c|c|}
\hline & \multicolumn{5}{|c|}{ Gestation at birth (weeks) } \\
\hline & $<32$ & $32-33$ & $34-36$ & $37-38$ & $39-41$ \\
\hline \multicolumn{6}{|l|}{ Any longstanding illness } \\
\hline At 3 years: & $(n=162)$ & $(n=158)$ & $(n=850)$ & $(\mathrm{n}=2911)$ & $(n=10080)$ \\
\hline No (\%) & $45(26.3)$ & $31(19.8)$ & $158(17.8)$ & $490(16.8)$ & $1482(15.1)$ \\
\hline Unadjusted odds ratio $(95 \% \mathrm{Cl})$ & 2.1 (1.4 to 3.2$)$ & $1.5(0.8$ to 2.5$)$ & $1.2(1.0$ to 1.5$)$ & $1.1(1.0$ to 1.3$)$ & 1 \\
\hline Adjusted ${ }^{*}$ odds ratio $(95 \% \mathrm{Cl})$ & $2.0(1.3$ to 3.1$)$ & $1.4(0.8$ to 2.4$)$ & $1.2(1.0$ to 1.5$)$ & $1.1(1.0$ to 1.3$)$ & 1 \\
\hline \multirow{2}{*}{$\begin{array}{l}\text { Adjusted* population } \\
\text { attributable fraction-\% (95\% } \\
\mathrm{Cl})\end{array}$} & $0.9(0.2$ to 1.7$)$ & $0.4(-0.2$ to 1.4$)$ & $1.1(-0.3$ to 2.7$)$ & \multirow[t]{2}{*}{$2.4(-0.5$ to 5.4$)$} & \multirow[t]{2}{*}{-} \\
\hline & & 1.5 & & & \\
\hline At 5 years: & $(n=166)$ & $(n=149)$ & $(n=855)$ & $(n=2851)$ & $(\mathrm{n}=9965)$ \\
\hline No (\%) & $59(35.9)$ & $43(30.6)$ & $219(25.6)$ & $561(19.8)$ & $1861(18.4)$ \\
\hline Unadjusted odds ratio $(95 \% \mathrm{Cl})$ & $2.6(1.7$ to 3.9$)$ & $2.0(1.4$ to 3.0$)$ & $1.6(1.3$ to 1.9$)$ & 1.1 (1.0 to 1.2$)$ & 1 \\
\hline Adjusted* odds ratio $(95 \% \mathrm{Cl})$ & 2.4 (1.6 to 3.8$)$ & $2.0(1.3$ to 2.9$)$ & 1.5 (1.2 to 1.8$)$ & 1.1 (1.0 to 1.2$)$ & 1 \\
\hline \multirow{2}{*}{$\begin{array}{l}\text { Adjusted }{ }^{*} \text { population } \\
\text { attributable fraction-\% }(95 \% \\
\mathrm{Cl})\end{array}$} & \multirow[t]{2}{*}{$1.2(0.4$ to 2.1$)$} & $0.9(0.2$ to 1.7$)$ & 2.6 (1.0 to 4.3$)$ & \multirow[t]{2}{*}{$1.3(-1.1$ to 3.7$)$} & \multirow[t]{2}{*}{-} \\
\hline & & & & & \\
\hline \multicolumn{6}{|c|}{ Any longstanding illness limiting child's activities } \\
\hline At 3 years: & $(n=162)$ & $(n=158)$ & $(n=850)$ & $(\mathrm{n}=2911)$ & $(n=10080)$ \\
\hline No (\%) & $21(12.2)$ & $11(8.1)$ & $46(5.7)$ & $87(2.8)$ & $270(2.7)$ \\
\hline Unadjusted odds ratio $(95 \% \mathrm{Cl})$ & $5.2(2.9$ to 9.1$)$ & $3.3(1.7$ to 6.6$)$ & $2.2(1.6$ to 3.1$)$ & $1.0(0.8$ to 1.4$)$ & 1 \\
\hline Adjusted* odds ratio $(95 \% \mathrm{Cl})$ & 4.5 (2.5 to 8.2$)$ & $3.4(1.7$ to 6.7$)$ & $2.1(1.4$ to 2.9$)$ & $1.0(0.8$ to 1.3$)$ & 1 \\
\hline \multirow{2}{*}{$\begin{array}{l}\text { Adjusted }{ }^{*} \text { population } \\
\text { attributable fraction- } \%(95 \% \\
\mathrm{Cl})\end{array}$} & \multirow[t]{2}{*}{$3.2(1.2$ to 5.6$)$} & $2.1(0.3$ to 4.4$)$ & $5.6(2.0$, to 9.9$)$ & \multirow[t]{2}{*}{$0.2(-4.5$ to 5.8$)$} & \multirow[t]{2}{*}{-} \\
\hline & & & & & \\
\hline At 5 years: & $(n=166)$ & $(n=149)$ & $(n=855)$ & $(n=2851)$ & $(n=9965)$ \\
\hline No (\%) & $32(18.6)$ & $21(13.9)$ & $79(8.7)$ & $198(6.7)$ & $532(5)$ \\
\hline Unadjusted odds ratio $(95 \% \mathrm{Cl})$ & 4.4 (2.8 to 6.9$)$ & $3.1(1.8$ to 5.4$)$ & $1.8(1.4$ to 2.4$)$ & $1.4(1.1$ to 1.7$)$ & 1 \\
\hline Adjusted* odds ratio $(95 \% \mathrm{Cl})$ & $3.9(2.4$ to 6.3$)$ & $3.0(1.7$ to 5.2$)$ & 1.7 (1.3 to 2.3$)$ & $1.3(1.1$ to 1.6$)$ & 1 \\
\hline \multirow{2}{*}{$\begin{array}{l}\text { Adjusted }{ }^{*} \text { population } \\
\text { attributable fraction—\% (95\% } \\
\text { Cl) }\end{array}$} & \multirow[t]{2}{*}{2.7 (1.1 to 4.3$)$} & $1.8(0.4$ to 3.5$)$ & $3.6(1.2$ to 6.5$)$ & \multirow[t]{2}{*}{5.4 ( 0.7 to 10.5$)$} & \multirow[t]{2}{*}{-} \\
\hline & & & & & \\
\hline
\end{tabular}

All percentages and odds ratios are weighted with sampling and non-response weights.

*Adjusted for child's age at interview, sex, and ethnicity; maternal age at birth, marital status, education, and occupation; whether child was mother's firstborn; duration of breast feeding; and maternal smoking and alcohol intake during pregnancy. 
Table 6 | Odds ratios of parent rating child's health as fair or poor compared with excellent, very good, or good at 5 years

\begin{tabular}{|c|c|c|c|c|c|}
\hline \multirow[b]{2}{*}{ Fair/poor health at 5 years } & \multicolumn{5}{|c|}{ Gestation at birth (weeks) } \\
\hline & $<32(\mathrm{n}=166)$ & $32-33(n=149)$ & $34-36(n=856)$ & $37-38(n=2852)$ & $39-41(n=9969)$ \\
\hline No (\%) & $17(8.1)$ & $15(8.7)$ & $48(5.5)$ & $151(4.8)$ & $385(3.5)$ \\
\hline $\begin{array}{l}\text { Unadjusted odds ratio }(95 \% \\
\mathrm{Cl})\end{array}$ & 2.7 (1.4 to 5.1$)$ & $2.9(1.6$ to 5.4$)$ & $1.7(1.2$ to 2.4$)$ & $1.4(1.1$ to 1.8$)$ & 1 \\
\hline Adjusted* odds ratio $(95 \% \mathrm{Cl})$ & 2.3 (1.0 to 4.5$)$ & $2.8(1.5$ to 5.5$)$ & 1.5 (1.1 to 2.1$)$ & 1.3 (1.0 to 1.7$)$ & 1 \\
\hline \multirow{2}{*}{$\begin{array}{l}\text { Adjusted }{ }^{*} \text { population } \\
\text { attributable fraction-\% } \\
(95 \% \mathrm{Cl})\end{array}$} & \multirow[t]{2}{*}{$1.3(0.0$ to 3.0$)$} & $1.6(0.2$ to 3.4$)$ & $2.8(0.1$ to 6.1$)$ & \multirow[t]{2}{*}{$5.5(-0.7$ to 12.1$)$} & \multirow[t]{2}{*}{-} \\
\hline & & & & & \\
\hline
\end{tabular}

All percentages and odds ratios are weighted with sampling and non-response weights.

*Adjusted for child's age at interview, sex, and ethnicity; maternal age at birth, marital status, education, and occupation; whether child was mother's firstborn; duration of breast feeding; and maternal smoking and alcohol intake during pregnancy. 
Table $7 \mid$ Odds ratios for asthma and wheezing

\begin{tabular}{|c|c|c|c|c|c|}
\hline \multirow{2}{*}{$\begin{array}{l}\text { Wheezing or whistling in } \\
\text { chest in previous } 12 \text { months }\end{array}$} & \multicolumn{5}{|c|}{ Gestation at birth (weeks) } \\
\hline & $<32$ & $32-33$ & $34-36$ & $37-38$ & $39-41$ \\
\hline At 3 years: & $(n=159)$ & $(n=157)$ & $(n=833)$ & $(n=2873)$ & $(n=9917)$ \\
\hline No (\%) & $63(37.7)$ & $42(26.8)$ & $214(23.3)$ & $600(20.2)$ & $1889(18.6)$ \\
\hline Unadjusted odds ratio $(95 \% \mathrm{Cl})$ & $2.9(1.9$ to 4.4$)$ & $1.8(1.2$ to 2.8$)$ & $1.4(1.2$ to 1.7$)$ & 1.1 (1.0 to 1.3$)$ & 1 \\
\hline Adjusted ${ }^{*}$ odds ratio $(95 \% \mathrm{Cl})$ & $2.6(1.7$ to 4.0$)$ & 1.7 (1.1 to 2.6$)$ & $1.3(1.0$ to 1.5$)$ & $1.1(1.0$ to 1.2$)$ & 1 \\
\hline At 5 years: & $(n=164)$ & $(n=148)$ & $(\mathrm{n}=853)$ & $(n=2845)$ & $(\mathrm{n}=9932)$ \\
\hline No (\%) & $56(34.1)$ & $34(23.0)$ & $183(20.9)$ & $486(17.2)$ & $1556(15.0)$ \\
\hline Unadjusted odds ratio $(95 \% \mathrm{Cl})$ & $3.1(2.0$ to 4.8$)$ & $1.8(1.1$ to 3.0$)$ & $1.6(1.3$ to 1.9$)$ & $1.2(1.1$ to 1.3$)$ & 1 \\
\hline Adjusted* odds ratio $(95 \% \mathrm{Cl})$ & $2.9(1.9$ to 4.6$)$ & 1.7 (1.0 to 2.8$)$ & $1.5(1.2$ to 1.8$)$ & $1.2(1.0$ to 1.3$)$ & 1 \\
\hline
\end{tabular}

All percentages and odds ratios are weighted with sampling and non-response weights.

*Adjusted for child's age at interview, sex, and ethnicity; maternal age at birth, marital status, education, and occupation; whether child was mother's firstborn; duration of breast feeding; and maternal smoking and alcohol intake during pregnancy. 
Table 8 | Odds ratios for use of prescribed asthma drugs at 5 years

\begin{tabular}{|c|c|c|c|c|c|}
\hline \multirow{2}{*}{$\begin{array}{l}\text { Prescribed asthma drugs } \\
\text { at } 5 \text { years }\end{array}$} & \multicolumn{5}{|c|}{ Gestation at birth (weeks) } \\
\hline & $<32(n=166)$ & $32-33(n=149)$ & $34-36(n=856)$ & $37-38(n=2851)$ & $39-41(n=9964)$ \\
\hline No (\%) & 17 (11.3) & $11(9.4)$ & $65(7.6)$ & $121(4.9)$ & $369(3.4)$ \\
\hline $\begin{array}{l}\text { Unadjusted odds ratio }(95 \% \\
\mathrm{Cl})\end{array}$ & 3.6 (1.8 to 7.13$)$ & 3.0 (1.5 to 5.8$)$ & $2.4(1.7$ to 3.3$)$ & $1.0(0.6$ to 1.9$)$ & 1 \\
\hline $\begin{array}{l}\text { Adjusted* odds ratio (95\% } \\
\text { Cl) }\end{array}$ & 3.5 (1.7 to 7.2$)$ & 2.8 (1.4 to 5.6$)$ & $2.2(1.6$ to 3.1$)$ & $1.4(1.1$ to 1.8$)$ & 1 \\
\hline
\end{tabular}

All percentages and odds ratios are weighted with sampling and non-response weights.

*Adjusted for child's age at interview, sex, and ethnicity; mother's age at birth, marital status, education, and occupation; whether child was mother's firstborn; whether child was ever breast fed; and smoking and drinking during pregnancy. 


\section{Figures}

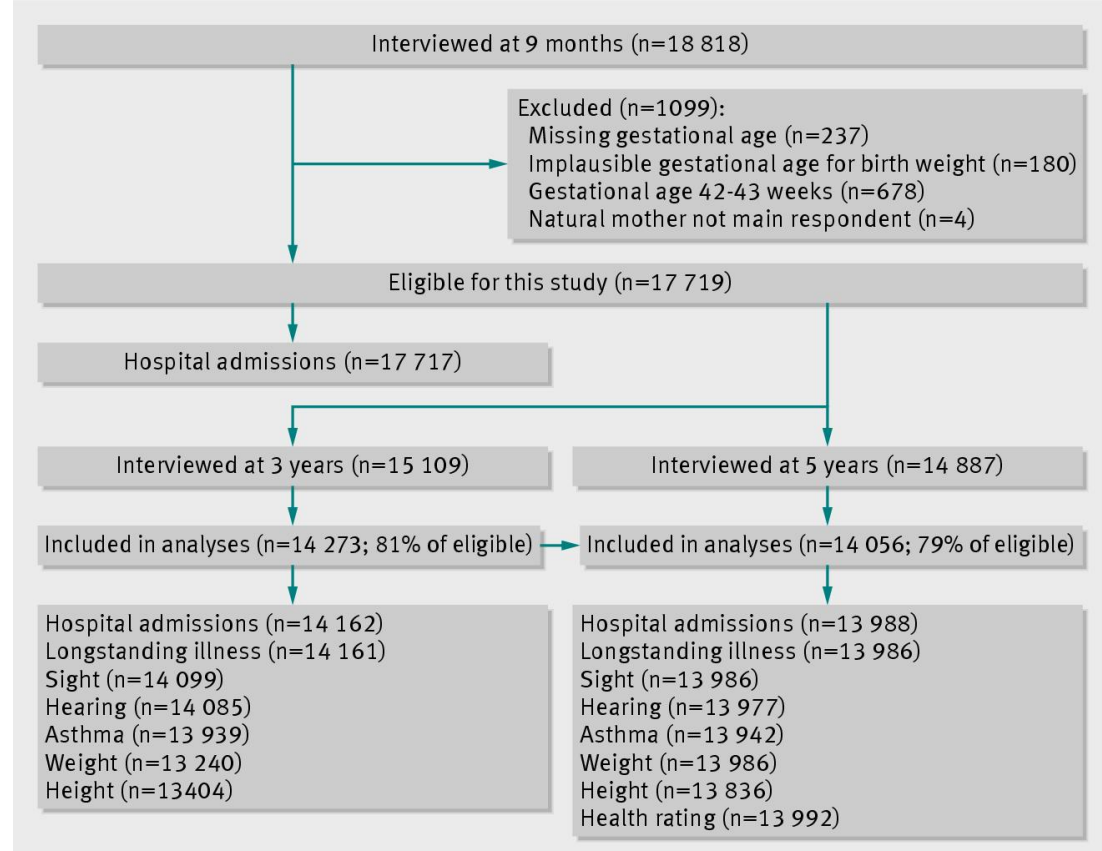

Fig 1 Flow chart of eligibility and participation
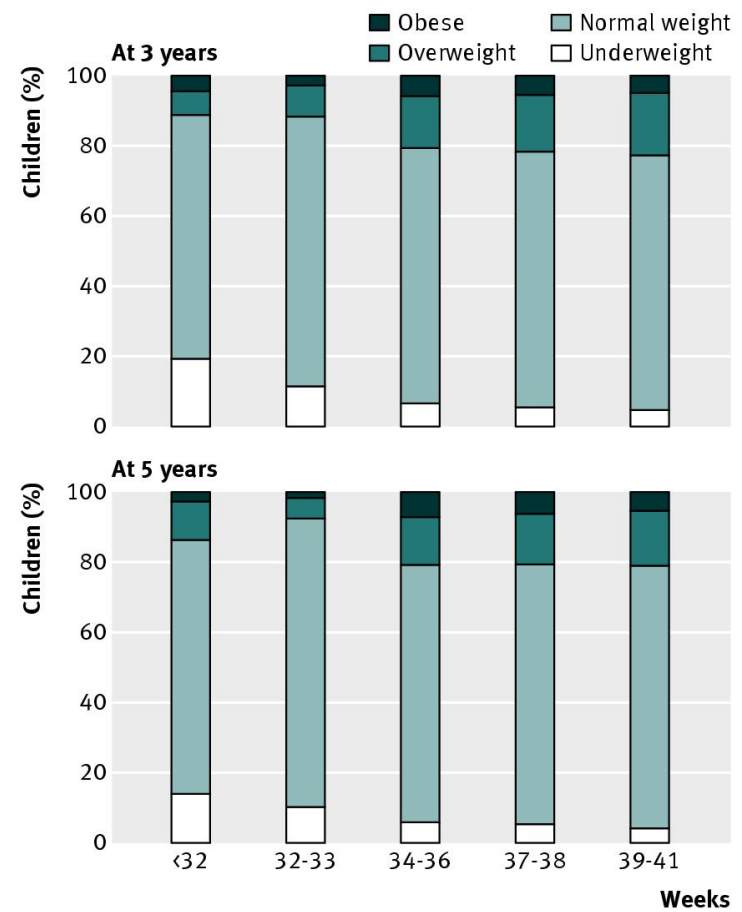

Fig 2 Classification of weight status according to body mass index at 3 and 5 years for gestational age groups 